\title{
Effecting Technical Management Reform at a Semi-Functional School: A Case Study of a School in an Informal Settlement in Gauteng, South Africa
}

\author{
Visvaganthie Moodley \\ University of Witwatersrand, Johannesburg, South Africa
}

\begin{abstract}
In response to the educational crisis in South Africa, a professional development programme (PDP) was initiated by the Gauteng Department of Education and University of Witwatersrand for school leaders of, mostly, dysfunctional schools. The aim was to develop school leadership with a focus on improving teaching and learning in the classroom. This study is informed by the framework of the PDP and theories of classroom pedagogies, particularly Sammons' et al. model of school effectiveness. Using the case study approach, it demonstrates the improvement in technical management made by a primary school principal over 2 years. The paper presents the challenges experienced at the school, the leadership practices engaged in, and the effects of the implementation of strategic leadership practices. It argues that positive changes in school management and leadership practices can occur through a PDP and concludes that attitudinal change and a conscious effort in implementing specific leadership practices can contribute to a systematic improvement in teaching and learning practices. Finally, it recommends that an evaluation of the effect that the PDP has had on overall school functionality, requires representative sampling of participating schools from the various districts of the province of Gauteng. It also recommends that to determine the effect that a PDP has on school functionality, it is necessary to evaluate not only technical management, but substantive management where learner outcomes are measured, as well.
\end{abstract}

\section{Introduction}

The educational crisis in South Africa reached a state of calamity when the PIRLS (2006) results [15] revealed that South Africa performed dismally, amidst 40 participating countries and 5 Canadian provinces, in both reading and math literacies. Coupled with this, school exiting (Grade 12) results were equally alarming: after 12 years of schooling, every year, for the years $2004-2007$, of the learners who reached Grade 12, $17 \%$ of school leavers achieved a university pass standard; 50\% passed but did not qualify with a university pass standard; and $33 \%$ failed. The statistics for the past 3 years shows no improvement: while there was a general increase of approximately $2 \%$ in post school pass rate, the overall pass deteriorated by approximately $5 \%$. This, as Bloch [2] notes, is 'despite vastly superior resources in Africa's most industrialized nation'. While given the political, educational and social history of South Africa there are numerous and diverse factors that contribute to the literacy and overall education crisis and that learners' cognitive outcomes rarely focus on social-affective outcomes, research such as those of Christie [4], [5] and Bloch [2] show that one of the most telling reasons for the creation of dysfunctional schools in South Africa mapped at between $60 \%-80 \%$ - is poor school management and leadership coupled with poor educator competence. The situation in South Africa is foreboding even as one considers comments such as those of Muhammad Ali Jinnah, in his address to the National Education Conference as far back as 1947. He stated: ' $\ldots$ the importance of education and type of education cannot be overemphasized ... there is no doubt that the future of [a] state will and must greatly depend upon the type of education we give our children.' [3].

In response to the educational crisis in South Africa, over the years 2008 and 2009, a partnership between University of Witwatersrand (WITS) and Gauteng Department of Education (GDE) was initiated to address the issue of dysfunctional schools. Underpinned by the principle that professional development programmes act as instruments of growth and renewal [11] a professional development programme, the Executive Leadership Programme (ELP), aimed at developing participants' capacity for improved leadership of teaching and learning at schools and building the knowledge and skills they need to become 'lead learners' in order to facilitate teachers' and learners' learning within a collaborative school culture, was offered to school managers and leaders. The programme itself was 'informal' in that even though it was structured for theory, content and instructional development, it was not an accredited course. Without instrumental gain, the intrinsic motivation to 
reform schools by invitee-participants was crucial. In each of the two years of implementation, approximately 180 schools in the larger Gauteng Province were identified and invited to participate. However, not all schools were dysfunctional; in each district at least one high achieving school was invited to share 'what was working' at their schools.

Within this context, the aims of this paper are to, by employing a case study approach, identify the challenges experienced at a primary school in a rural area in Gauteng and show the degree of improvement the school leader-participant claims to have made over 2 years, since the implementation of the ELP. This paper argues that positive, technical management and leadership changes, strategies for which are offered by an informally structured PDP, can affect school based teaching and learning practices, in varying degrees.

\section{Methodology and data collection procedures}

Using the case study approach, within a qualitative paradigm, data was obtained from a school profile information sheet (provided in questionnaire format), the principal-participant's portfolio of work (an essential component of the programme) and an individual semi-structured, recorded interview. The profile information sheet captured the status of the school with regard to teaching and learning resources, and its infrastructure; the linguistic and educational profile of its teachers; the linguistic profile and scholastic performance of its learners; and an open-ended question for further comments that were not captured by the close ended questions. The principal's portfolio of work comprised assignments (compulsory tasks and additional self-tasks) that were based on keynote speakers' addresses at the seminars, readings in the form of books and articles, and discussions led by the facilitator - all of which focussed on improving technical management to effect change in teaching and learning practices. The core questions of the interview schedule was intended to capture the profile of the principal, determine the challenges experienced at the school, her reflections of the ELP, and to ascertain how, as claimed in her presentation to the ELP group and external educationist-evaluators (a compulsory concluding activity to the ELP), the ELP seminars had contributed to addressing identified challenges and effecting changes in teaching and learning practices as well as the general, routine functioning of the school. The selection of this principal, (hereafter, Mrs Q) was purposeful in that she was one of the participants who showed significant progress in school technical management and becoming a 'lead learner' for improved culture of teaching and learning at her school. With regard to ethical issues, as the interview could have yielded unfavourable perceptions of the school, managers, teachers, learners, parents and the community as a whole, special care was taken to adhere to ethical demands.

\section{Literature review}

Various definitions of 'dysfunctional schools' have been proffered; however, for the purposes of this paper, I adopt Christie's [4] and Gallie's [10] versions. Christie refers to the 'poor functioning' of predominantly Black schools located in the 'poor and disrupted communities spawned by apartheid', schools which experience (and continue to experience) 'breakdown in the culture of teaching and learning'. Gallie defines dysfunctional schools as those which continue to 'exist' but [which] do not accomplish the purposes for which they were created. Nevertheless, the state of functionality is not a dichotomous one; schools can be plotted onto any point of the functional-dysfunctional continuum. In their study of dysfunctional schools in South Africa, Christie [4], [5] and Perumal [14] show that dysfunctional schools in general display the following features - all of which have a detrimental impact on the core work of teaching and learning: poor physical and social facilities; serious organizational problems - including weak and unaccountable leadership and administrative dysfunction (for example, difficulties in drawing up time-tables), poor communication, and inadequate disciplinary and grievance procedures; poor relationships with surrounding community; poor communications and interactions with the education department; questionable pedagogic practices; and unqualified or under- qualified teaching staff. In the late seventies, Edmonds [6] in his study of characteristics of effective schools identified 'strong leadership of the principal' as the most influential factors for effective schools. In South Africa, this is a critical characteristic in that principal appointments are not always done on competence but, as the ELP group discussion revealed, are politically orchestrated by dominant teacher unions. Consequentially, combined with the aftermath of a shackling Bantu education [13], schools are further disabled by having teachers who lack pedagogical content knowledge. To add to these complexities, English is a barrier to teaching and learning for the large majority of South African school teachers and children, English is their additional language. Clearly, such schools require drastic reform if they are not to be shut down altogether, as some schools have been.

There appears to be consensus on literature on school improvement viz. successful educational change requires both central policy mandates, such 
as system-wide standards, and 'school by school' assistance [9]. According to Fleish [8], at its most general, school reform models may be broadly divided into 3 categories - technical, political and cultural - categories which are not mutually exclusive. The ELP was articulated within these 3 models: it was situated within political and cultural frameworks (to do otherwise in a country fraught with political and educational injustices since its colonization in the mid $17^{\text {th }}$ century and one where cultural and linguistic diversity is the norm, would be fundamentally deficient) but built strongly on the technical model aimed at improving schools at a micro-level. This acknowledges research such as those of Fullan [9] and Silbert [17] which show that there exists a general failure of school initiative programmes, mostly as a result of, as Slavin [18] and Fleish [8] note, models not being based on substantial evidence that proves improved student outcomes. However, as it is not within the power of the PDP to effect system-wide standards such as distribution of resources, the ELP focussed on school by school assistance, implementing strategies that could directly impact on the daily functions of teachers and learners in the classroom.

On examining effective management of a school, a key consideration by the ELP was the recognition of schools as formal organizational institutions. Such organizations function on a regular set of rituals and norms which create cohesion among the participants. According to Enslin and Pendlebury [7] when schools function well, they provide an organizational environment for systematic formalized teaching and learning. In South Africa, structural forms of day to day management such as assemblies, teacher and learner registers, uniforms, resources, policies, curriculum and the like are controlled by the state. In spite of such 'controls' however, the actual functioning of each school and the degree of adherence to policy is questionable, hence, as Christie [5] points out, far too many schools show clear signs of organizational breakdown. Clearly, given the dynamics of the breakdown in the culture of teaching and learning, regeneration of schools as functioning organizations is not a quick fix. In identifying the degree of dysfunctionality of the participating schools of the ELP, the following set of criteria was used: the school ethos; vision, aims and strategic planning; principal's leadership qualities; collaborative leadership practices of the principal, school management and teachers; organizational structure of the school; decision making and communication; links with parents and community; professional working relationship; and schools as agents of change. Accordingly, the school of this study (hereafter, School P) could be defined as semifunctional with a tendency towards dysfunctionality.

The ELP, intended to address the challenge of dysfunctional schools can therefore be seen as an attempt at chipping away at the iceberg of disorganization and pedagogical incompetence. As such, every step towards progress is significant for the particular school and not necessarily for regeneration for the country as a whole. The ELP was informed by various educational management, and teaching and learning models, of which, according to Hallinger and Murphy [12], instructional leadership is predominant. This paper, however, focuses on technical management rather than substantive management as the former was the principal outcome of the ELP. Drawing on the various models, particularly Sammons' et al. [16] model of school effectiveness and with the view that critical school leadership is inextricably linked to the notion of distributive leadership, as noted by Perumal [14], I used the following characteristics in determining the improvement made at School P.

\section{LEARNING AND TEACHING}

The school principal:

- Professional leadership

- Attitude and motivation

- Vision for the school/ Shared goals

- Knowledge of educator staff

- Knowledge of learner population

- Partnership with community

- Visibility, monitoring, evaluation and feedback

- Mentoring strategies

- Working collaboratively

The teacher:

- Attitude and Motivation

- Time on task

- Purposeful teaching

- High expectations

- Content knowledge

- Pedagogical knowledge

- Classroom management

- Creating literacy rich learning environment

- Professional development

The learner:

- Attitude and Motivation

- Active participation

- Desire to achieve

- Time on task

- Reading and writing literacies

Other:

- Resources

- Conducive environment

- Facilities

- Co-curricular and Extracurricular activities

The ELP has identified the principal and his/her management team as principal figures of agents that 
can - through theoretical understanding, attitudinal change, taking ownership of the school, assisting in developing knowledge and skills for successful planning and implementation of school improvement initiatives, creating a collaborative school culture, focusing on the task of teaching, and developing capacity for improved leadership - create a functional organization that improves teaching and learning practices. These were facilitated within the following structure: 10 plenary seminars led by key note educationist-speakers on topics pertinent to the issues mentioned above, and 10, 8 hour face-to-face interactions between groups of school principals and facilitators known as syndicate leaders. Each syndicate leader facilitated a group of $15-20$ participants and was responsible, through collaborative interactions, for guiding the participants through the following cycle of activities (see Figure 1).

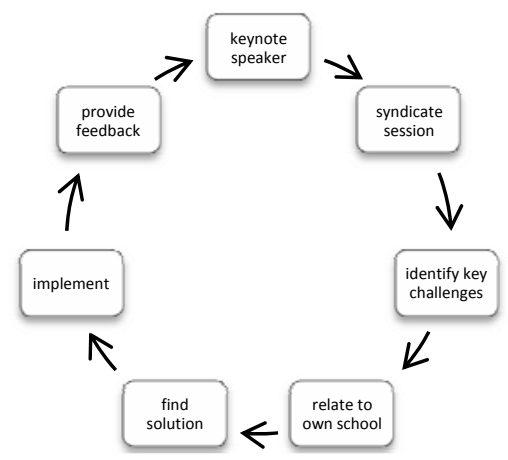

Figure 1. Cycle of activities

As a concluding activity of the programme, each school participant(s) was required to present a portfolio of work which addressed the above and present a PowerPoint presentation of strengths and challenges of the school, the key areas of concern and how they had used the knowledge and skills acquired from the ELP to improve the level of functionality at their respective schools.

\section{Findings and discussion}

The primary school, School $\mathrm{P}$, situated in an informal settlement, comprised 1640 learners and 43 educators (inclusive of management staff). The general class size ranged from 48 to 55 learners. The school was described as under-resourced and that which did not have a library, adequate furniture and playground. Their textbooks are stored in cupboards. The home language of both educators and learners is an African language (the dominant languages being Tswana, Zulu and Xhosa), and English, which is the medium of instruction, is their additional language. While the large majority holds a teaching diploma (obtained from a Bantu education system) [13], not all teachers hold teaching qualifications in the subjects they were teaching. No information on the strengths of the school was provided. This factual description of the school viz. poor resources, large class numbers, English as a teaching and learning barrier, and by inference, poor teacher pedagogical content knowledge of subject being taught are characteristics as indicated earlier, which create a breeding ground for low school functionality. A poor socio-economic environment is generally accompanied by low parental expectations of the school and this tends to permeate the classroom where teachers themselves have low expectations of their learners. The challenges that Mrs Q identified were: educator attitude and motivation; educator subject expertise; text book use and management; teacher accountability; over-crowded classrooms; time on task; numeracy foundations for learning; literacy foundations for learning; assessment; focused monitoring; professional development; and conflict with unions. Drawing mostly from data provided in the portfolio (which included critical reflective practices), the concluding PowerPoint presentation and the recorded interview, using the framework of learning and teaching presented earlier, I shall focus on what emerged as more significant in addressing the challenges at the school of this study viz. principal and teacher characteristics which include: principal's leadership qualities; teacher accountability; time on task; text book use and management; professional development programmes for teachers; and changing pedagogies for effective learning.

\subsection{Principal's leadership qualities}

The interview recording and reflective tasks show that Mrs Q's own positive attitude and motivation was enhanced by the ELP's initial seminar on attitude and motivation, and the need to take ownership of the school. The salient characteristics that she displayed to bring about change at the school were her drive to improve the quality of learner outcomes; her enthusiasm to try out ideas discussed at the ELP seminars; her assertiveness in demanding accountability from her teachers; her ability to provide evidence when confronting the unresponsive teacher; her initiative in arranging and even providing small group, in-school professional development workshops; and her determination to resist teacher union interference by doing classroom visits, and monitoring curriculum compliance and learner progress by examining learners' books. Mrs Q said that initially she was 'very anxious' about the demands of the ELP, especially the feedback and evidence that was required after implementing certain required tasks but was also 'excited and motivated [that] really useful knowledge and skills were given in a scaffolded and practical way [so that 
she] could try them out'. What clearly emerged from the interview was that the technical management strategies that were provided systematically helped create pathways for a more organized leadership.

\subsection{Teacher accountability}

In responding to the challenge of teacher accountability, Mrs Q collated what emerged from the various ELP seminars (for example, need for lesson plans, teaching methodologies, use of educational taxonomies for teaching and assessment, and collaborative decision making among teachers) and implemented strategies at the school by becoming more assertive with her teachers, exacting accountability with regard to: daily lesson plans; coherence between number of periods and activities set for a class; evidence of learners' written work for periods which are usually accounted for as 'oral work' or 'group work'; use of both summative and formative assessments rather than only the latter as was the previous practice at the school in spite of curriculum policy for 'continuous assessment'; evidence of collaborative setting and moderation of test papers; and evidence of mentoring of the uncoping teacher by school management teams. According to Mrs Q, these changes challenged previous 'complacent [and] lackadaisical' practices and low learner expectations, and individual resistant teachers were 'confronted individually'. The changes actioned were crucial for the overall functional organization of the school and while the substantive effects could not be measured, she claimed that there were overall visible improvement to the culture of teaching and learning at the school.

\subsection{Time on task}

In her interview, Mrs Q reflected on interactions during the syndicate contact sessions at the ELP and imparted how she implemented what she had learnt at the session. She stated that previously she had not calculated or even heeded the amount of time teachers actually spent outside the classroom when they should have been in their classrooms; she 'had never calculated the wasted minutes'. However, since the issue of wasted time in movement by both teacher and learner to the classroom after assembly and intervals was discussed at the syndicate session, she became conscientized about the obligation that teachers have to their learners 'to be present in their classes' and to 'use their time optimally'. Mrs Q stated that she, together with her deputy principal, embarked on an 'observation and note-making campaign' on teacher movement to the classroom after assembly, in the mornings. She noted that teachers would stand around talking and 'dragging their feet' to their classrooms. She quoted a teacher who spent the time that should have been in class, making photocopies and who reported to her class in the final 15 minutes of 40 minute period, having wasted almost $63 \%$ time on task. Mrs Q addressed the teacher on the issue and followed up with an 'interactive meeting' with her staff. This intervention was something new to the staff and Mrs Q met with some resistance to the 'policing'. Nevertheless, she made her teachers aware of their obligations to their learners and claims to have the large majority of teachers in their classrooms when they should be.

\subsection{Text book use and management}

The issue of text books to learners in South Africa is fraught with difficulties as poor practical care of, and taking responsibility for loaned text books, is a problem at many dysfunctional schools. Some of the problems to this regard, as indicated by the ELP participants include learners not carrying books to school as 'they are too heavy [and some] have to walk long distances to school, misuse of books, and loss of books without replacement due to poverty of parents. Hence, at School P, the books gathered dust in cupboards. This, of course, as Mrs Q acknowledged after a discussion on the issue of textbooks, exacerbated the literacy crisis at her school. On this note she stated: 'You made us realize that how can they learn how to read when they don't have the books to read? And this thing about the teacher writing everything on the chalkboard it's so much time wasted. Now, more real work is covered in the 40 minutes'. Books at this school are now issued: learners are given practical instruction of the value of and care of books, and parents are required to sign for the books loaned. Mrs Q claims that since the 'text book revolution' at her school, teachers have more quality contact time with their learners as the previous habit of 'writing everything on the chalkboard' has freed the teacher to engage more meaningfully with learners.

\subsection{Professional development programmes for teachers}

One of the most significant influences that the syndicate group discussion had on promoting teacher content and pedagogical knowledge was the initiation of small in-school professional development workshops at various schools. By using the expertise of qualified and competent teachers of the school as well as others outside the school, mini-in-school workshops were provided on content information of certain math literacy topics, reading strategies, establishing reading corners in each classroom, and replicating a development programme on assessment for higher order thinking that I had given at the ELP. Mrs Q stated that the unqualified and under-qualified math teachers who themselves 'do not understand certain math concepts 
they have to teach' now feel more confident about their teaching; that reading is no longer just 'reading aloud the words in the book'; and that all test and exam papers now undergo rigorous internal moderation that is aligned with the curriculum statements. These mini workshops have provided both affective and pedagogical benefits. The affective benefits are that teachers have safe supportive spaces where they feel comfortable to seek assistance and mentorship from 'others who know' and the pedagogical benefits are that their own pedagogic content knowledge is enhanced. Mrs Q stated that this turnabout has been and continues to be the most challenging, as organizing the workshops will be ineffectual 'if teachers [themselves] don't change their own attitudes about wanting to make a change in their classrooms'.

\subsection{Changing pedagogies for effective learning}

The issue of pedagogies was a key factor of focus at the ELP seminars - my own focus was on strategies for reading for meaning and scaffolding questions from lower to middle to higher order for promoting cognitive development. Mrs Q transferred her own learning to her teachers by offering a workshop on questioning techniques using Bloom's taxonomy [1]; discussing techniques for group work on a one to one basis with her language teaching team; providing remedial reading to learners whom her teachers identified as 'weak readers'; and emphasizing the need for writing for almost all language activities, including writing during oral activities. Mrs Q had impacted sufficiently the attitudes and motivation of her language team so that they could initiate various interclass competitions (for example, reading, writing and spelling competitions) and a book club for teachers at the school to encourage their own reading practices. The foci on pedagogy, if sustained, augers well for changing reading, thinking and writing patterns amongst learners but requires teachers to have sound content knowledge. Clearly, research needs to be extended into the classroom to ascertain the substantive effect of implementation of newly acquired strategies and practices

\section{Conclusions}

Mindful of the subjective element of interviews, this paper demonstrates that specific changes that affect the core work of teaching and learning at a micro level can be initiated at dysfunctional schools through a professional development programme that offers both theoretical understanding and practical assistance for school by school. The case of School P which was purposefully selected, demonstrates that the characteristics outlined within Sammons' et al.[14] adapted framework of learning and teaching are critical for any degree of reform at schools which are not functioning at desirable levels. This study supports Edmond's [6] findings that the most significant agent of change at a school is the school principal. S/he is the pulse of the school who must enthuse teachers to till the soil of old, barren teaching and learning practices and embrace changes. Teachers need to recognize that they are powerful resources in the classroom and that by collaborating with more knowledgeable others [19] they can become critical agents of change. This paper concludes that the catalyst for positive change is acknowledgement of the dysfunctional elements at the school, consciousness raising of need for change of attitude towards teaching and learning by staff, learners and the community, and systematic addressing of prioritized challenges. However, this paper does not claim overall effectiveness as this is a purposeful case study. Rather, it recommends that to evaluate the effect that the PDP has had on overall school functionality, requires representative sampling of schools from the various districts of the province of Gauteng. Finally, in supporting Fleish's [87], Silbert's [17] and Slavin's [18] and view on a model that is based on substantive evidence, it also recommends that professional development programmes should be grounded in a twin model so that it can be evaluated on, not only technical management, but substantive management where learner outcomes are measured, as well.

\section{References}

[1] Anderson, L. and Krathwohl, D. (eds.) (2001) A Taxonomy for Learning, Teaching, and Assessing: A Revision of Bloom's Taxonomy of Educational Objectives, Longman, New York.

[2] Bloch, G. (2009) The Toxic Mix: What's Wrong with South Africa's Schools and How to Fix it, Tafelberg, Cape Town.

[3] Campaign for Quality Education (2007) 'Education in Pakistan: What Works and Why’, Lahore, Pakistan.

[4] Christie, P. (2008) Opening the Door of Learning, Heinemann, South Africa.

[5] Christie, P. (1998) 'Schools as (dis)organizations: The "breakdown of the culture of teaching and learning" in South Africa', Cambridge Journal of Education, 28 (3), pp 283-300.

[6] Edmonds, R. (1979) 'Effective Schools for the Urban Poor’, Educational Leadership, 37 (1), pp 20-24.

[7] Enslin, P. and Pendlebury, S. (1998) 'Transforming Education in South Africa', Cambridge Journal of Education, 28 (3), pp 261-267. 
[8] Fleish, B. (2002) Managing Educational Change, The State and School Reform in South Africa, Heinemann, South Africa.

[9] Fullan, M. (2001) New Meaning of Educational Change, $3^{\text {rd }}$ edition, Teachers College Press, New York.

[10] Gallie, M. (2009) 'The State of Education. Where are we?' Paper Presentation at the Executive Leadership Programme, University of Witwatersrand, Johannesburg, South Africa.

[11] Goderya-Shaikh, F. (2010) 'Professional Development with Follow-up for an Effective Paradigm Shift', International Journal for Cross-Disciplinary Subjects in Education (IJCDSE), 1(3), pp 182-189.

[12] Hallinger, P. and Murphy, J. (1986) 'The Social Context of Effective Schools', American Journal of Education, 94 (3), pp 328-355.

[13] Jansen, J. (1990) 'Curriculum as a Political Phenomenon: Historical Reflections on Black South African Education', The Journal of Negro Education 59 (2), pp 195-206.

[14] Perumal, J. (2009) 'Reading and creating critically leaderful schools that make a difference: the post-apartheid South African case', International Journal Leadership in Education, 12 (1), pp 35-49.

[15] PIRLS (Progress in International Reading Literacy Study) (2007) Overview of PIRLS 2006 Results'; http://www.iea.nl/fileadmin/user_upload/PIRLS2006/Over view_Results.pdf (25 October 2010).

[16] Sammons, P., Hillman, J. and Mortimore, P. (1995) 'Key Characteristics of Effective Schools: A review of school effectiveness research. A report by the Institute of Education for the Office for Standards in Education'; http://www.le.ac.uk/se/ESI/doc1f.html (28 October 2010).

[17] Silbert, P. (2008) 'Diversity and School Reform: A Critique of the Scholarship on School Effectiveness and School Improvement', in Educational Change in South Africa: Reflections on Local Realities, Practices and Reforms, Weber, E. (ed.) Sense Publishers, The Netherlands, pp 149-165.

[18] Slavin, R. (2001) 'Putting the School back in School Reform.’ Education Leadership, 58 (4), pp 22-27.

[19] Vygotsky, L.S. (1978). Mind and society: The Development of Higher Mental Processes, Harvard University Press, Cambridge. 